\title{
Determinación de atrazina e intermediarios de biodegradación en enriquecimientos bacterianos provenientes de cursos de agua superficial de Uruguay
}

\section{Determination of atrazine and its biodegradation intermediates in}

\section{bacterial enrichments obtained from Uruguayan water courses}

\author{
Da Cunha, Jonathan (1), Pinelli, Laura ${ }^{(1)}$, Bellini, María Inés ${ }^{(1)}$, Davyt, Danilo ${ }^{(2)}$, Fernández-Scavino, Ana ${ }^{(1)}$ \\ (1) Laboratorio Ecología Microbiana y Microbiología Ambiental, Departamento de Biociencias - (2) Laboratorio de Quími- \\ ca Farmacéutica, Departamento de Química Orgánica, Facultad de Química, UdelaR, Montevideo, Uruguay. \\ Contacto: afernand@fq.edu.uy
}

Recibido: 17/5/2013 - Aprobado: 23/11/2013

\begin{abstract}
$\underline{\text { Resumen }}$
La atrazina es un herbicida que se utiliza para el control de malezas anuales y gramíneas perennes. Aunque se encuentra prohibido en la Unión Europea por su toxicidad y la de sus metabolitos, en Uruguay ocupa el segundo lugar de importancia en volúmenes de importación. La presencia de atrazina ha sido especialmente relevante en algunos cursos de agua que surten a las plantas potabilizadoras nacionales. El principal mecanismo de eliminación de la atrazina en ambientes con pH neutro es la degradación bacteriana. Los microorganismos pueden degradar atrazina produciendo intermediarios de variada persistencia y toxicidad, o mineralizarla dando amonio y anhídrido carbónico. La separación y detección de estos intermediarios es importante para seleccionar consorcios bacterianos apropiados para aplicar en un proceso de biorremediación. En este trabajo se desarrolló un método isocrático de cromatografía líquida de alta performance (HPLC) usando un agente de par iónico y fase reversa para separar atrazina de algunos de sus metabolitos en un medio de cultivo sintético. Este método resultó adecuado para detectar los intermediarios de la degradación producidos por consorcios bacterianos autóctonos seleccionados. También se utilizó para determinar si un consorcio bacteriano activo podía degradar la atrazina adsorbida sobre carbón activado.

Palabras clave: Atrazina, metabolitos, HPLC, biodegradación, aguas superficiales.
\end{abstract}

\begin{abstract}
$\underline{\text { Abstract }}$
Atrazine is an herbicide used to control annual weeds and perennial grasses. Due to the toxicity of atrazine and its metabolites, this herbicide is banned in the European Union. In Uruguay atrazine is the second most frequently imported herbicide. It has been detected in surface water courses, particularly those that provide water for potabilization plants. The main mechanism for atrazine removal in neutral $\mathrm{pH}$ environments is the bacterial degradation. The microorganisms can degrade atrazine giving intermediates that vary in persistence and toxicity, or mineralize it giving ammonia and carbon dioxide. The separation and detection of atrazine intermediates of biological degradation is important to know the potential of bacterial consortia to be applied in bioremediation processes. In this paper we developed an isocratic method of high performance liquid chromatography (HPLC) by ion-pair reversed phase to separate atrazine and metabolites in a synthetic culture medium. This method was useful to detect intermediates of atrazine degradation produced by selected native bacterial consortia. In addition, the method was employed to assess if atrazine adsorbed on activated carbon could be degraded by an active degrading consortium.
\end{abstract}

Keywords: Atrazine, metabolites, HPLC, biodegradation, surface water.

\section{Introducción}

La atrazina, 1-cloro-3-etilamino-5-isopropilamino-2,4,6-triazina, se utiliza para el control de malezas anuales y gramíneas perennes. Es un herbicida que ha sido prohibido en la Unión Europea desde 2006, pero en Uruguay es el segundo en importancia con una tendencia al incremento de las importaciones en los últimos años (MGAP, 2011). Se utiliza especialmente en cultivos de soja, mezclado con glifosato, para controlar el trébol blanco y otras malezas que han desarrollado resistencia al glifosato.

La atrazina ocasiona trastornos del sistema endócrino (Salaberria et al., 2009) y puede afectar los sistemas nervioso (Rodríguez et al., 2005) y reproductor (Cooper et al., 2000).

Recientemente ha causado alarma pública en Uruguay la presencia de atrazina en cursos de agua superficiales, especialmente en algunos que se usan como fuente de agua para las plantas potabilizadoras (El 
País Digital, 2010). El incremento del uso de agroquímicos y de la superficie cultivable ha desencadenado este problema ambiental que en las plantas potabilizadoras se resuelve adsorbiendo la atrazina, y los otros potenciales contaminantes, con carbón activado.

El principal mecanismo de eliminación de la atrazina de ambientes con $\mathrm{pH}$ neutro es la degradación bacteriana. Hasta hace 30 años se había observado que la atrazina era degradada lentamente por monooxigenasas inespecíficas que no sostenían el crecimiento microbiano y daban lugar a un variado espectro de intermediarios metabólicos. Entre estos productos se observaron los intermediarios desalquilados de la hidroxiatrazina, la desetilhidroxiatrazina y la desisopropilhidroxiatrazina (Erickson y Lee, 1989). Posteriormente se han encontrado bacterias, solas o en consorcios, capaces de degradar completamente la atrazina por una vía hidrolítica que comienza con la declorinación y producción de hidroxiatrazina (reacción que también puede ser abiótica); esta vía también tiene como intermediario importante al ácido cianúrico (Udiković-Kolić et al., 2012). Esta evolución de la capacidad metabólica bacteriana es prometedora para aplicar en procesos de biorremediación de atrazina, ya que transcurre rápidamente y mineraliza completamente el herbicida. Para explorar esta capacidad metabólica en microorganismos autóctonos es necesario contar con métodos analíticos apropiados para caracterizar el proceso y los intermediarios de degradación en condiciones de laboratorio, en las cuales las concentraciones utilizadas son muy superiores a las permitidas por las autoridades sanitarias.

El HPLC ha sido la metodología más utilizada para la determinación de atrazina y sus metabolitos de degradación microbiana en medios de cultivo relativamente sencillos (Mandelbaum et al., 1993; Radosevich et al., 1995; Lin et al., 2008) y en muestras ambientales que representan matrices más complejas como aguas superficiales y suelo (Vermulen et al., 1982; Karlaganis et al., 1991; Steinheimer, 1993). La cromatografía gaseosa acoplada a espectrometría de masas (GC/ MS), más sensible para la determinación de atrazina y sus metabolitos (Patnaik, 1997), tiene la desventaja de que requiere derivatizar los compuestos para el análisis. En la metodología de HPLC se han estudiado diferentes condiciones de trabajo, tales como cromatografía en fase ligada con columnas amino (Dufek et al., 1980) o ciano (Smolkova y Pacakova, 1978), así como también en fase reversa con columna C8 (Vermulen et al., 1982; Mandelbaum et al., 1993) o C18, esta última la más utilizada. La mayoría de estas variantes se aplicó para la determinación de atrazina, pero no para sus metabolitos.

Beilstein et al. (1981) han estudiado por HPLC en fase reversa con columna C18 la separación de 17 triazinas, entre ellas la atrazina y los metabolitos, incluyendo al ácido cianúrico. Si bien estos autores pudieron determinar la totalidad de los compuestos, la separación no fue buena. Desde entonces no se han reportado otros estudios de separación de todos los metabolitos junto a la atrazina. El ácido cianúrico es un compuesto hidrofílico muy polar que eluye en el frente de corrida en los sistemas adecuados para separar los demás metabolitos en fase reversa. Otros estudios han hecho énfasis en la determinación del ácido cianúrico en aguas de piscina (Downes et al., 1982; Hou y Ding, 2011) o en leche en polvo (Hou y Ding, 2011) por HPLC en fase reversa con columna $\mathrm{C} 18$ o en medio de cultivo utilizando HPLC en columna de intercambio iónico de fase ligada con aminas (Jesee et al., 1981). Según este autor, a pH próximo a la neutralidad el ácido cianúrico se encuentra en su forma enol, por lo que en solución con un compuesto iónico de carga positiva se podría formar un par iónico entre ambos compuestos. Debido a esto, Hou y Ding (2011) plantearon la determinación del ácido cianúrico mediante una cromatografía de par iónico con el agregado de bromuro de tetrabutilamonio (TBAB) a la fase móvil, utilizando condiciones de fase reversa con una columna C18. Los autores lograron así la determinación del ácido cianúrico con un límite de detección de 0,3 ppm y una buena separación del frente de la corrida.

El objetivo de este trabajo es optimizar un método isocrático de HPLC que permita la determinación de atrazina, hidroxiatrazina, desetilhidroxiatrazina, desisopropilhidroxiatrazina y ácido cianúrico en las concentraciones utilizadas en enriquecimientos bacterianos obtenidos en diferentes condiciones de cultivo.

\section{Materiales y Métodos}

\section{Optimización de la determinación de atrazina y metabolitos por HPLC}

Los estándares de atrazina, hidroxiatrazina, desetilhidroxiatrazina, desisopropilhidroxiatrazina y ácido cianúrico (Tabla 1) calidad ppa (puro para análisis) fueron adquiridos en Sigma-Aldrich. Se prepararon soluciones patrón de $100 \mathrm{mg} / \mathrm{l}$ en medio acuoso para ácido cianúrico, en metanol para atrazina y en acetonitrilo para los demás compuestos. Se utilizaron solventes calidad HPLC y agua calidad milli-Q. El hidróxido de tetrabutilamonio (TBAOH) fue utilizado como reactivo de par iónico (12,5\% en metanol, Sigma Aldrich).

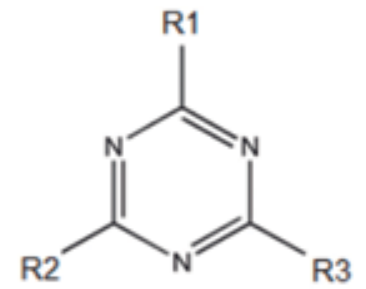

\begin{tabular}{|l|c|c|c|c|}
\hline Compuesto & Abreviatura & R1 & R2 & R3 \\
\hline Atrazina & AT & cloro & etilamino & isopropilamino \\
\hline Hidroxiatrazina & HA & hidroxilo & etilamino & isopropilamino \\
\hline Desetilhidroxiatrazina & DEHA & hidroxilo & etilamino & isopropilamino \\
\hline Desisopropilhidroxiatrazina & DIHA & hidroxilo & hidroxilo & amino \\
\hline Ácido Cianúrico & AC & hidroxilo & hidroxilo \\
\hline
\end{tabular}

Tabla 1. Nombres, abreviaturas y estructuras de los metabolitos analizados. 
En la optimización del método analítico se utilizaron estándares de atrazina ( $11 \mathrm{mg} / \mathrm{l})$ y de sus metabolitos ( $2 \mathrm{mg} / \mathrm{l}$ de cada uno) en fase acuosa y en medio de cultivo MDA previamente esterilizado.

La determinación de atrazina y sus metabolitos se realizó con un HPLC marca Shimadzu, con bomba LC-10AD operada en modo isocrático, volumen de inyección de $20 \mu \mathrm{l}$ y un detector espectrofotómetrico (modelo UV SPD-10, Shimadzu) con lámpara de deuterio a la longitud de onda de $220 \mathrm{~nm}$. Las condiciones cromatográficas seleccionadas fueron: una columna C8 Lichrospher select B marca Lichrocart de 250x4,0 mm, tamaño de poro de $60 \AA$ y tamaño de partícula de $5 \mu \mathrm{m}$, fase móvil de acetonitrilo/TBAOH $3 \mathrm{mM}$ en buffer fosfato $0,01 \mathrm{M}, \mathrm{pH} 7 \mathrm{y}$ con el gradiente de flujo (F) programado que sigue: de 0 a $8 \mathrm{~min}, \mathrm{~F}=0,5 \mathrm{ml} / \mathrm{min}$; de 8 a $10 \mathrm{~min}$ aumento progresivo hasta $\mathrm{F}=1,5 \mathrm{ml} / \mathrm{min}$; de 10 a $18 \mathrm{~min}$ se mantuvo este flujo; de 18 a $20 \mathrm{~min}$ aumento progresivo hasta $\mathrm{F}=2,0 \mathrm{ml} / \mathrm{min}$; de 20 a 40 min se mantuvo este flujo. El límite de detección para la atrazina y para sus metabolitos fue de $0,5 \mathrm{mg} / 1$.

\section{Medio de cultivo MDA}

El $\mathrm{pH}$ de este medio de cultivo se ajusta a 7,2 y su composición es: $\mathrm{K}_{2} \mathrm{HPO}_{4} 18 \mathrm{mM}, \mathrm{KH}_{2} \mathrm{PO}_{4} 6 \mathrm{mM}$, trazas de minerales $5 \mathrm{ml} / \mathrm{l}$ (Touzel y Albagnac, 1983) y atrazina comercial (90\% pureza, Novazina 90GD) $25 \mathrm{mg} / \mathrm{l}$. Después de esterilizar en autoclave a $121{ }^{\circ} \mathrm{C}$ por $15 \mathrm{~min}$, se agregaron los siguientes componentes esterilizados por filtración: solución de vitaminas (Touzel y Albagnac, 1983) 0,9 ml/1, $\mathrm{CaCl}_{2}$ 0,5 mM y $\mathrm{MgSO}_{4} 1 \mathrm{mM}$. La mezcla de fuentes de carbono y energía también se esterilizó por filtración y se agregó al medio base autoclavado: acetato de sodio $0,7 \mathrm{mM}$, ácido succínico $0,7 \mathrm{mM} \mathrm{y}$ citrato de sodio $0,7 \mathrm{mM}$. En este medio de cultivo la única fuente de nitrógeno es atrazina a una concentración cercana a su máxima solubilidad en agua. En los enriquecimientos suplementados con una fuente de nitrógeno adicional se agregó $\mathrm{KNO}_{3}(22 \mathrm{mg} / \mathrm{l}$ de nitrato).

\section{Determinación de atrazina y metabolitos en enriquecimientos bacterianos en medio acuoso}

Se estudió la presencia de intermediarios de la degradación microbiana de atrazina en medio MDA en enriquecimientos incubados en condiciones similares a las de los sistemas ambientales donde estos consorcios podrían ser aplicados. Sólo algunas bacterias son capaces de degradar atrazina en presencia de fuentes alternativas de nitrógeno como nitrato, frecuentemente encontrado en aguas superficiales y subterráneas. Por otra parte, las temperaturas próximas a $20^{\circ} \mathrm{C}$ son las más cercanas a las ambientales de una planta de potabilización.

Se prepararon enriquecimientos inoculados con aguas de ríos de la cuenca lechera de Uruguay. En la primavera de 2011 se tomaron muestras de las aguas que ingresaban a las plantas potabilizadoras de Aguas Corrientes (río Santa Lucía en Canelones) y Dolores (río San Salvador en Soriano). Se incubó el agua extraída suplementada con 25 $\mathrm{mg} / \mathrm{l}$ de atrazina comercial en viales aerobios en dos temperaturas (20 y $30^{\circ} \mathrm{C}$ ), en ausencia y en presencia de nitrato. Después de observar turbidez debida al crecimiento se subcultivó en medio MDA con atrazina y se incubó en las mismas condiciones. Se seleccionaron los enriquecimientos que degradaban atrazina (Pinelli et al., 2012). Se analizó el sobrenadante obtenido después de centrifugar $10.000 \mathrm{~g}$ con la metodología optimizada en este trabajo para determinar si se acumulaban intermediarios de la degradación.

\section{Biodegradación de atrazina adsorbida sobre carbón activado}

El ensayo se realizó en viales color ámbar de $300 \mathrm{ml}$ con $60 \mathrm{ml}$ de medio MDA. Se preparó el medio MDA sin atrazina y con carbón activado (Alpha W610) en polvo $1200 \mathrm{mg} / \mathrm{l}$. Se esterilizó en autoclave a $121{ }^{\circ} \mathrm{C}$ por $15 \mathrm{~min}$, luego se agregó atrazina comercial a partir de una solución metanol-agua concentrada, previamente autoclavada, para dar una concentración final de $30 \mathrm{mg} / 1$ y una relación carbón activado:atrazina de 40:1.

El inóculo que se empleó consistió en el consorcio bacteriano degradador de atrazina ACLD 25.2, obtenido previamente en el laboratorio, el cual puede degradar $25 \mathrm{mg} / \mathrm{l}$ del herbicida en 24 horas. Brevemente, este consorcio se obtuvo a partir de lodo de la pileta de decantación de la planta potabilizadora de Aguas Corrientes, OSE, luego de 15 subcultivos en medio MDA (Pinelli et al., 2012). Antes de inocular se confirmó que el inóculo degradara el $100 \%$ de la atrazina soluble en medio MDA en un período de $24 \mathrm{hs}$.

Para extraer la atrazina adsorbida se filtró el volumen total $(60 \mathrm{ml})$ de cada vial por un filtro de papel Whatman. Se conservó el sobrenadante acuoso a $-20{ }^{\circ} \mathrm{C}$ hasta su análisis. La extracción de atrazina adsorbida en el carbón se realizó tratando el carbón y el filtro de papel en un matraz de $250 \mathrm{ml}$ con $100 \mathrm{ml}$ de metanol a $20^{\circ} \mathrm{C}$ con agitación orbital durante $48 \mathrm{hs}$. Se recuperó el sobrenadante alcohólico por filtración en filtro de poliamida y se congeló a $-20{ }^{\circ} \mathrm{C}$ hasta su análisis. Se cuantificó por HPLC la cantidad de atrazina en el sobrenadante en metanol (adsorbida) y en el sobrenadante acuoso (no adsorbida).

El ensayo se realizó en 20 viales que se procesaron a diferentes tiempos para determinar la cantidad de atrazina y metabolitos, tanto los adsorbidos al carbón activado como los que quedaron en el sobrenadante acuoso del medio de cultivo. Los viales con medio MDA, carbón activado y atrazina se pre-incubaron en oscuridad durante 4 días a $30^{\circ} \mathrm{C}$, con agitación, para asegurarse la adsorción de la atrazina sobre el carbón activado. Luego se inocularon 12 viales con $5 \%$ de inóculo fresco del consorcio ACLD 25.2 que se mantuvieron incubándose en las mismas condiciones. Adicionalmente, se incubaron 4 viales sin inocular (controles abióticos). Los restantes 4 viales fueron procesados para cuantificar la atrazina del sobrenadante acuoso y la adsorbida al momento de la inoculación (tiempo 0). Los viales inoculados se procesaron después de 4, 11 y 17 días de inoculados y los controles abióticos se analizaron a los 17 días de incubados.

\section{Resultados y Discusión}

\section{Optimización de la determinación de atrazina y metabolitos en matrices acuosas}

En este trabajo se logró poner a punto un método isocrático para separar algunos metabolitos de atrazina que, si bien demanda mayores tiempos de corrida para la separación, permite la utilización de un equipo más sencillo (con una sola bomba). Además, posibilita el reciclado de la fase móvil que disminuye la contaminación y el costo del análisis. El trabajo cubre un rango de metabolitos de biodegradación posibles más acotado que el reportado en la literatura (Udiković-Kolić et al., 2012). Sin embargo, estos metabolitos han sido encontrados como intermediarios de la degradación en varios microorganismos y no es posible conocer a priori cuál vía utilizará un consorcio degradador determinado. Asimismo, otros metabolitos reportados no difieren sustancialmente en su estructura química de los ensayados, por lo cual sería posible integrar nuevos metabolitos a la metodología desarrollada.

El grado de similitud en las estructuras de los dos intermediarios desalquilados, que solo difieren en un grupo metilo, fue el primer problema en abordar dado que la separación cromatográfica en fase reversa se basa en las diferencias de hidrofobicidad que presentan los compuestos a separar. Se ensayaron variantes en la fase móvil con dos solventes orgánicos y diferentes concentraciones. Se trabajó con metanol y acetonitrilo (en adelante ACN) en dos concentraciones para cada fase orgánica: $40 \%$ y $60 \%$ para metanol, $17 \%$ y $20 \%$ para 
$\mathrm{ACN}$. Aunque las separaciones con todas las condiciones fueron buenas, se seleccionó la concentración de $17 \%$ de $\mathrm{ACN}$ porque separó mejor los compuestos desalquilados. Se ensayaron dos flujos, $1 \mathrm{ml} /$ min y $0,5 \mathrm{ml} / \mathrm{min}$, y se encontró que este último mejoraba mucho la separación de estos dos compuestos tan similares. Los tiempos de retención, expresados en minutos, fueron: 3,8 (AC), 6,0 (DIHA), 6,2 (DEHA), 16,8 (HA) y 70 para AT. La disminución de la concentración de ACN mejoraría la separación de los compuestos desalquilados pero aumentaría aún más el tiempo de retención de la AT, debido a la falta de fuerza del solvente para hacerla eluir de la columna. Con estas condiciones se obtuvieron similares tiempos de retención entre AT y HA que los obtenidos por Vermulen et al. (1982) en condiciones cromatográficas diferentes.

Para disminuir el tiempo de análisis y mantener la separación de los metabolitos más similares se trabajó con el gradiente de flujo que se describe en la sección Materiales y Métodos. En la Figura 1a se muestra el cromatograma obtenido en estas condiciones que permitieron reducir el tiempo de elución de atrazina de 70 min a 37,6 $\min$.

Para evitar la elución del AC con el frente de la corrida se ensayó una cromatografía de par iónico modificada de Hou y Ding (2011). Se utilizó hidróxido de tetrabutilamonio (TBAOH) como reactivo de par iónico en concentración de $3 \mathrm{mM}$ en la fase móvil ACN/buffer fosfato $0,01 \mathrm{M} \mathrm{pH}$ 7,00 (17:83). En la Figura 1b se muestra el cromatograma obtenido del análisis de la solución acuosa de los estándares con estas condiciones; se pudo observar que el AC tiene un tiempo de retención de 4,8 min, mientras que sin el TBAOH eluye a los 4,0 min. En la Figura $1 \mathrm{~b}$ también se puede ver que el TBAOH no tuvo efecto apreciable sobre la elución del resto de los compuestos. Con estas condiciones se obtuvieron tiempos de retención similares para el AC que los obtenidos por Hou y Ding (2011).
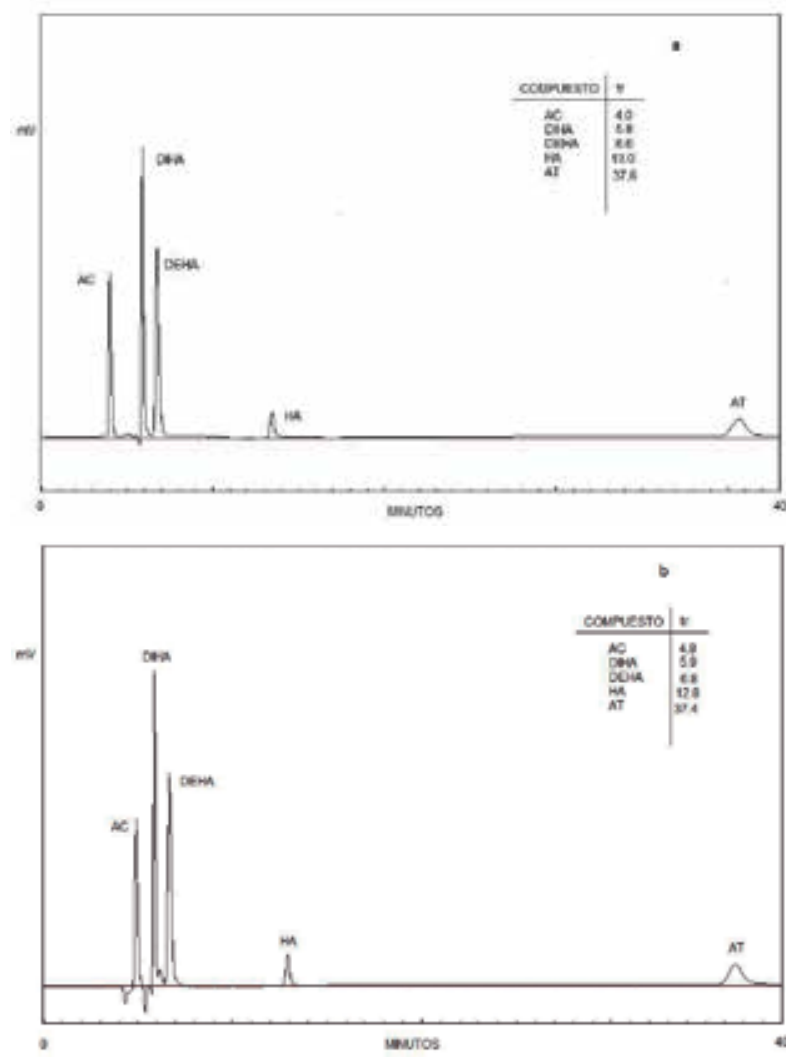

Figura 1. Cromatograma de separación por HPLC con gradiente de flujo de una mezcla de $2 \mathrm{mg} / \mathrm{l}$ en solución acuosa de: AC (ácido cianúrico), DIHA (desisopropilhidroxiatrazina), DEHA (desetilhidroxiatrazina), HA (hidroxiatrazina) y AT (atrazina), utilizando como fase móvil: (a) ACN/buffer fosfato $0.01 \mathrm{M} \mathrm{pH} 7$ (17:83); (b) ACN/buffer fosfato $0.01 \mathrm{M} \mathrm{pH} 7$ (17:83), TBAOH $3 \mathrm{mM}$
En la Figura 2 se observa el efecto de la matriz sobre la determinación de AC. El medio MDA contiene ácidos que pueden formar par iónico con el TBAOH y que podrían interferir con la determinación de AC. En esta figura se puede apreciar que el pico del AC en MDA presenta un ensanchamiento en la base, que se podría deber a la interferencia de alguno de los ácidos presentes en el MDA. $\mathrm{El}$ aumento relativo del área de $\mathrm{AC}$ en MDA respecto a la fase acuosa fue del orden del $10 \%$.

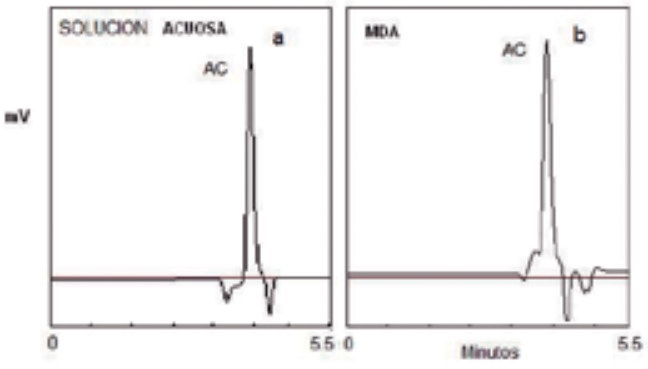

Figura 2. Efecto de la matriz en la elución del AC con fase móvil ACN/ buffer fosfato 0,01 M pH 7 (17:83), TBAOH 3 mM: (a) fase acuosa; (b) medio MDA.

\section{Aplicación del método para la caracterización de enriquecimientos degradadores de atrazina en medio acuoso}

Se realizó una caracterización metabólica de enriquecimientos degradadores de AT en MDA. En la Figura 3 se muestran los análisis de los metabolitos acumulados luego de la incubación de cuatro enriquecimientos diferentes. Las diferencias fueron el origen del inóculo (Aguas Corrientes o Dolores), las condiciones de incubación (temperatura y presencia o ausencia de nitrato) y el número de subcultivos sucesivos. En la Figura 3a se observa que en el enriquecimiento con inóculo de Aguas Corrientes, incubado a $30^{\circ} \mathrm{C}$ con nitrato, se acumula AC en el medio y se degrada la AT completamente. Los restantes análisis corresponden a enriquecimientos realizados a partir de aguas de Dolores. En las Figuras 3b y 3c se muestran los metabolitos acumulados de dos subcultivos sucesivos, incubados a $30{ }^{\circ} \mathrm{C}$ y con nitrato. Se puede observar que en el enriquecimiento 9.2 (Figura 3c) posterior al enriquecimiento 9 (Figura 3b) la degradación de AT es menor y la acumulación de HA mayor. Esta información permite conocer cuáles son los pasos de la vía de degradación que son más vulnerables en este enriquecimiento. Dado que se trata de un conjunto de bacterias con diferentes capacidades metabólicas que actúan concertadamente, es necesario conocer cuáles son los microorganismos o actividades más lábiles en el consorcio y que por tanto deben reforzarse para mantener la capacidad mineralizadora de estas asociaciones de bacterias. En la Figura 3d se muestra que en el enriquecimiento del mismo origen que los dos anteriores (Dolores) pero incubado a $20{ }^{\circ} \mathrm{C}$ sin nitrato, la AT se degrada completamente y se acumula AC. Este perfil es similar al de la Figura 3a, de origen y condiciones de incubación diferentes, lo que indica que estos factores pueden ser útiles para seleccionar consorcios degradadores con diferentes perfiles de intermediarios. Estos resultados señalan que el método optimizado en este trabajo permite distinguir el perfil metabólico de los consorcios bacterianos degradadores de atrazina en enriquecimientos obtenidos en diferentes condiciones. 

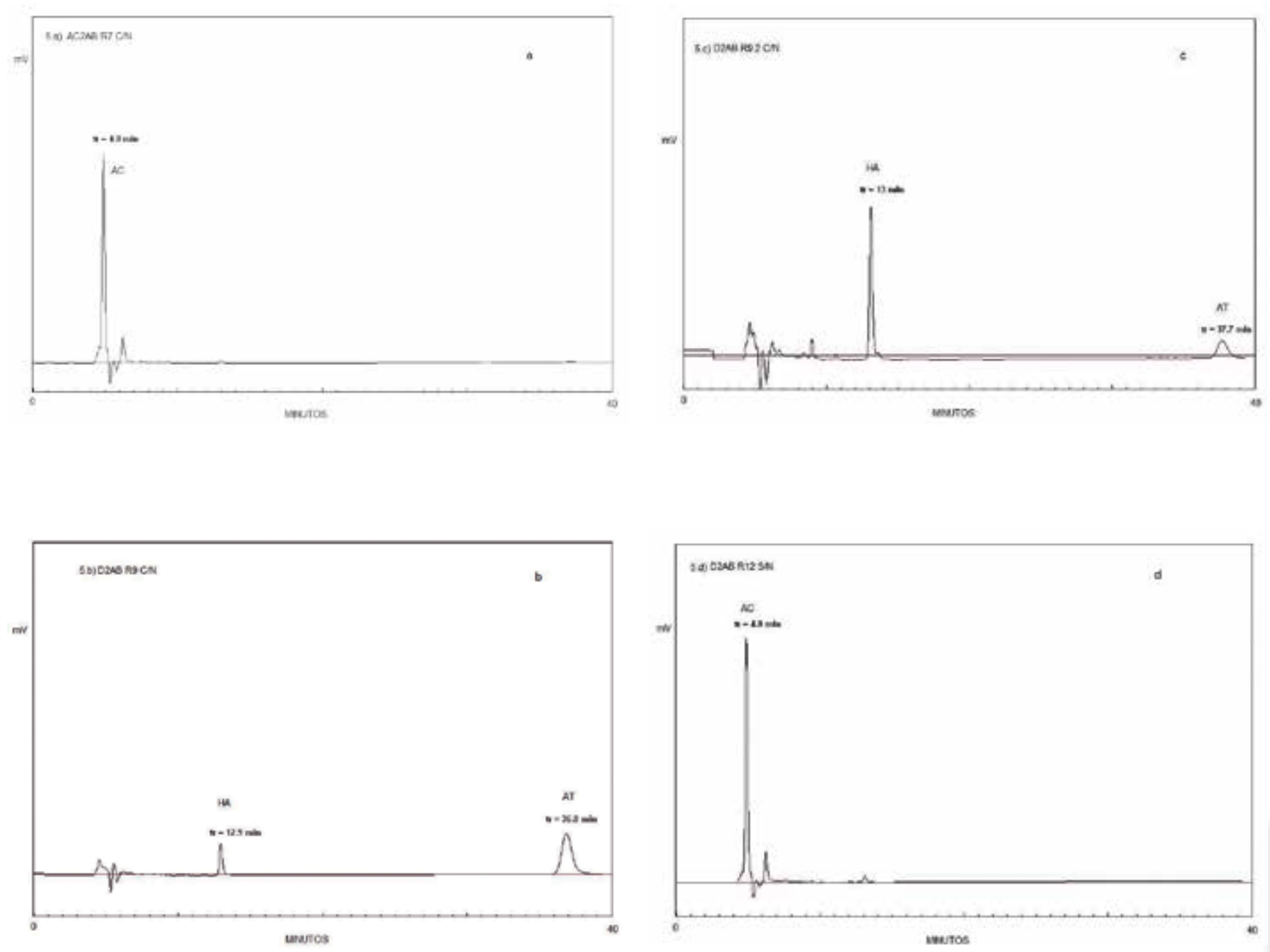

Figura 3. Perfil de atrazina y metabolitos acumulados por diferentes enriquecimientos bacterianos analizados por HPLC: a) enriquecimiento (subcultivo 7) proveniente de Aguas Corrientes incubado con nitrato a $30^{\circ} \mathrm{C}$; b) enriquecimiento (subcultivo 9) proveniente de Dolores incubado con nitrato a $30^{\circ} \mathrm{C} ; \mathrm{c}$ ) ídem a b) (subcultivo 9.2); d) enriquecimiento (subcultivo 12) proveniente de Dolores incubado sin nitrato a $20^{\circ} \mathrm{C}$.

\section{Aplicación del método para determinar la biodegradación de atrazina adsorbida sobre carbón activado}

La relación 40:1 de C activado a atrazina permitió que el herbicida se adsorbiera completamente. Durante la incubación no se observó atrazina en el sobrenadante acuoso de ningún vial, por lo que el herbicida permaneció adsorbido al carbón en todos los tratamientos y condiciones. Sin embargo, esta relación C:atrazina no permitió una buena recuperación de la atrazina adsorbida mediante su extracción con metanol. En los controles abióticos a tiempo 0 y después de 18 días de incubación se recuperó 30 y 32\% de atrazina, respectivamente (Tabla 2). A pesar de que la extracción con metanol ha sido ampliamente recomendada en la bibliografía (Ghosh y Philip, 2005; Aktas y Cecen, 2007), probablemente la alta relación C:atrazina disminuyó los rendimientos. En un análisis previo en nuestro laboratorio en el que la relación C:atrazina fue de 2:1, se recuperó el $100 \%$ de atrazina con el mismo procedimiento de extracción. Se eligió la relación 40:1 porque es la que emplea OSE para adsorber atrazina y otros compuestos que se encuentran en el agua bruta a la entrada de las plantas de potabilización.

En la Tabla 2 se observa que en los viales inoculados con los consorcios activos se recuperó la misma cantidad de atrazina que en los controles abióticos. Aun después de 17 días de incubación, la atrazina adsorbida no fue degradada por el consorcio bacteriano. Esto

\begin{tabular}{|l|c|c|c|c|}
\hline & \multicolumn{4}{|c|}{ Tiempo de incubación (días) } \\
\cline { 2 - 5 } & $\mathbf{0}$ & $\mathbf{4}$ & $\mathbf{1 1}$ & $\mathbf{1 7}$ \\
\hline Control abiótico & $30 \pm 4$ & nd & nd & $32 \pm 1$ \\
\hline Ensayo inoculado & nd & $38 \pm 3$ & $32 \pm 1$ & $30 \pm 3$ \\
\hline
\end{tabular}

Tabla 2. Porcentaje de recuperación de atrazina adsorbida sobre carbón activado durante la incubación en medio MDA inoculado con el consorcio bacteriano ACLD25 y no inoculado (Control abiótico). Desviación estándar de 4 replicados. En todos los casos la concentración de atrazina en el sobrenadante fue menor que el límite de detección $(0.5 \mathrm{mg} / \mathrm{l})$. nd: no determinado.

podría explicarse porque el C activado en polvo se aglomera después de la inoculación y disminuye el área de contacto entre las bacterias y los poros. Por otra parte, debido a que el tamaño de poro es del orden de los nm, el acceso de las bacterias a esos poros es difícil y solo si hay una desorción paulatina y reversible los microorganismos tendrían acceso a la atrazina. Se verificó que los consorcios inoculados permanecían viables y activos a los 15 y 21 días, ya que crecieron en placas de TSA y degradaron el $100 \%$ de atrazina disuelta en medio MDA sin C activado.

Se han utilizado filtros de C activado inoculados con bacterias para la remoción de atrazina de aguas superficiales (Jones et al., 1998; Zanini, 2010). Por otra parte, también se han utilizado microorganismos 
para regenerar el Carbón activado empleado como adsorbente. La bioregeneración de carbón activado es un proceso biológico económico y potencialmente eficiente para recuperar la capacidad adsorbente del carbono. Es un proceso amigable con el medio ambiente que utiliza los microorganismos para degradar los compuestos adsorbidos. La eficiencia de la bioregeneración depende de parámetros fisicoquímicos que faciliten la desorción y de la capacidad degradadora de los microorganismos (Nath et al., 2011). El proceso es factible si hay un gradiente de concentración del compuesto adsorbido entre el carbón y el sobrenadante o si los microorganismos degradadores producen exoenzimas capaces de alcanzar el compuesto en los diminutos poros del adsorbente (Aktas y Cecen, 2007). Por ello, esta biotecnología merece ser estudiada en mayor profundidad en condiciones similares a las ambientales y manejando parámetros fisicoquímicos que exploten la actividad metabólica de los microorganismos autóctonos.

\section{Conclusiones}

La modificación de la composición de la fase móvil, con el agregado de un agente de par iónico, y el gradiente de flujo permitieron optimizar un método isocrático para separar atrazina de algunos de sus productos de degradación microbiana en solución acuosa y en medio de cultivo.

Además, se pudo comprobar que el método resulta adecuado para distinguir diferentes capacidades metabólicas en enriquecimientos microbianos de bacterias autóctonas de distinto origen e incubados en diferentes condiciones.

La fuerte adsorción de atrazina al carbón activado no permitió determinar si un consorcio bacteriano eficiente en la degradación de atrazina soluble puede actuar sobre la atrazina adsorbida.

\section{Reconocimientos}

Financiación: Comisión Sectorial de Investigación Científica, UdelaR (Proyecto CSIC -SP 603). Agencia Nacional de Innovación e Investigación, Uruguay (Proyecto de Iniciación a la Investigación de JDC).

Colaboración en la coordinación y el muestreo en las plantas de potabilización, Laboratorio Central de OSE. Agradecemos especialmente a la Ing. Quim. Gianella Bonari.

Agradecimiento al Prof. Javier Menes, quien proporcionó la columna de HPLC para los análisis.

\section{Referencias}

- AKTAS, O.; CECEN, F. Bioregeneration of activated carbon: a review. En: International Biodeterioration \& Biodegradation. 2007, 59:257-272.

- BEILSTEIN, P.; COOK, A. M.; HUTTER, R. Determination of seventeen s-triazine herbicides and derivatives by high-pressure liquid chromatography. En: Journal of Agricultural and Food Chemistry. 1981, 29:1132-1135.

- COOPER, R. L.; STOCKER, T. E.; TYREY, L.; GOLDMAN, J. M.; MCELROY, W. K. Atrazine disrupts the hypothalamic control of pituitary-ovarian function. En: Toxicological Sciences. 2000, 53:297-307.

- DOWNES, C. J.; MITCHELL, J. W.; VIOTTO, E. S.; EGGERS, N. J. Determination of cyanuric acid levels in swimming pool waters by UV absorbance HPLC and melamine cyanurate precipitation. En: Water Research. 1982, 18:277-280.

- DUFEK, P.; PACÁKOVÁ, V.; TESAROVÁ, E. Separation and behavior of s-triazine derivatives on a NH2-chemically bonded stationary phase by high performance liquid chromatography. En: Journal of Chromatography. 1980, 191:115-120.

- EL PAÍS DIGITAL. Crece el nivel de herbicida en cuenca de Santa Lucía [En línea]. Montevideo: El País Digital, 2010. [Consulta: 19 de noviembre de 2013]. Disponible en: http://www.elpais.com. uy/100209/pciuda-470256/ciudades/crece-el-nivel-deherbicida.

- ERICKSON, L. E.; LEE, K. H. Degradation of atrazine and related s-triazines. Critical reviews En: Environmental Control. 1989, 19:1-14.

- GHOSH, P. K.; PHILIP, L. Performance evaluation of waste activated carbon on atrazine removal from contaminated water. En: Journal of Environmental Science and Health Part B. 2005, 40:425-441.

- HOU, S.; DING, M. Determination of cyanuric acid in milk powder \& swimming pool water by ion pair reversed phase liquid chromatography. En: Chinese Journal of Chemistry. 2011, 29:783786.

- JESSE, J. A.; VALERIA, C.; BENOIT, R. E.; HENDRICKS, A. C.; MCNAIR, H. M. Determination of cyanuric acid by high-performance liquid chromatography. En: Journal of Chromatography. 1981, 207:454-456.

- JONES, L. R.; OWEN, S. A.; HORRELL, P.; BURNS, R.G. Bacterial inoculation of granular activated carbon filters for the removal of atrazine from surface water. En: Water Research. 1998, 32:2542-2549.

- KARLAGANIS, G.; VON ARX, R.; AMMON, H. U.; CAMENZIND, R. High-performance liquid chromatographic determination of atrazine, deisopropylatrazine and deethylatrazine in soils from corn fields. En: Journal of Chromatography. 1991, 549: 229-236.

- LIN, T.; WEN, Y.; JIANG, L.; LI, J.; YANG, S.; ZHOU, Q. Study of atrazine degradation in subsurface flow constructed wetland under different salinity. En: Chemosphere. 2008, 72:122-128.

- MANDELBAUM, R. T.; WACKETT, L. P.; ALLAN, D. L. Mineralization of the s-triazine ring of atrazine by stable bacterial mixed cultures. En: Applied and Environmental Microbiology. 1993, 59:1695-1701.

- MGAP. Importación de productos fitosanitarios [En línea]. Montevideo: Uruguay, 2011. [Consulta: mayo de 2013]. Disponible en: http://www.mgap.gub.uy/dgssaa/DivAnalisisDiagnostico/ DAYD_PROFIT_ESTADISTICA.htm

- NATH, K.; BHAKHAR, M. S.; PANCHANI, S. Bioregeneration of spent activated carbon: effect of physico-chemical parameters. En: Journal of Scientific \& Industrial Research. 2011, 70:487-492.

- PATNAIK, P. Handbook of environmental analysis. Florida: CRC Press, 1997

- PINELLI, L.; DA CUNHA, J.; BELLINI, M. I.; FERNANDEZSCAVINO, A. Selección y caracterización de consorcios de bacterias como herramientas de biorremediación de la contaminación por atrazina en plantas potabilizadoras de agua [En línea]. En: UNIVERSIDAD DE LA PLATA. Actas del $7^{\circ}$ Congreso de Medio Ambiente AUGM, 2012. La Plata: Universidad Nacional de la Plata. [Consulta: mayo de 2013]. Disponible en: http://congresos.unlp.edu.ar/index.php/CCMA/7CCMA/paper/ viewFile/978/247

- RADOSEVICH, M.; TRAINA, S. J.; HAO, Y.; TOUVINEN, O. H. Degradation and mineralization of atrazine by soil bacterial isolate. En: Applied and Environmental Microbiology. 1995, 61:297-302. 
- RODRÍGUEZ, M. V.; THIRUCHELAVAM, M.; CORY-

SLETCHA, D. A. Sustained exposure to the widely used herbicide atrazine: altered function and loss of neurons in brain monoamine systems. En: Environmental Health Perspectives. 2005, 113:708715.

- SALABERRIA, I.; HANSENC, B. H.; ASENSIOA, V.; OLSVIKD, P. A.; ANADERSENB, R. A.; JENSSEN, B. M. Effects of atrazine on hepatic metabolism and endocrine homeostasis in rainbow trout (Oncorhynchus mykiss). En: Toxicology and Applied Pharmacology. 2009, 234:98-106.

- SMOLKOVA, E.; PACAKOVA, V. Liquid chromatographic separation and behaviour of some substituted s-triazines on a CNbonded stationary phase. En: Chromatographia. 1978, 12:698702.

- STEINHEIMER, T. R. HPLC determination of atrazine and principal degradates in agricultural soils and associated surface and ground water. En: Journal of Agricultural and Food Chemistry. 1993, 41:588-595.

- TOUZEL, J. P.; ALBAGNAC, G. Isolation and characterization of Methanococcus mazei strain MC3. En: FEMS Microbiology Letters. 1983, 16:241-245.

- UDIKOVIC-KOLIC, N.; SCOTT, C.; MARTIN-LAURENT, M. Evolution of atrazine-degrading capabilities in the environment. En: Applied Microbiol Biotechnology. 2012, 96:1175-1189.

- VERMULEN, N. M. J.; APOSTOLIDES, Z.; POTGIETER D. J. J; NEL, P. C.; SMIT, N. S. H. Separation of atrazine and some of its degradation products by high performance liquid chromatography. En: Journal of Chromatography. 1982, 240:247-253.

- ZANINI, J. Estudo da remoção do herbicida atrazina por biofiltração em filtros lentos de areia e carvão ativado associada à ação microbiana [En línea]. Sao Paulo: Faculdade de Engenharia, UNESP, 2010. [Consulta: mayo de 2013]. Disponible en: http:// www.acervodigital.unesp.br/handle/123456789/61402 